\section{Research Of Technological Parameters Of Pattern Cotton-Silk Knitting Fabrics}

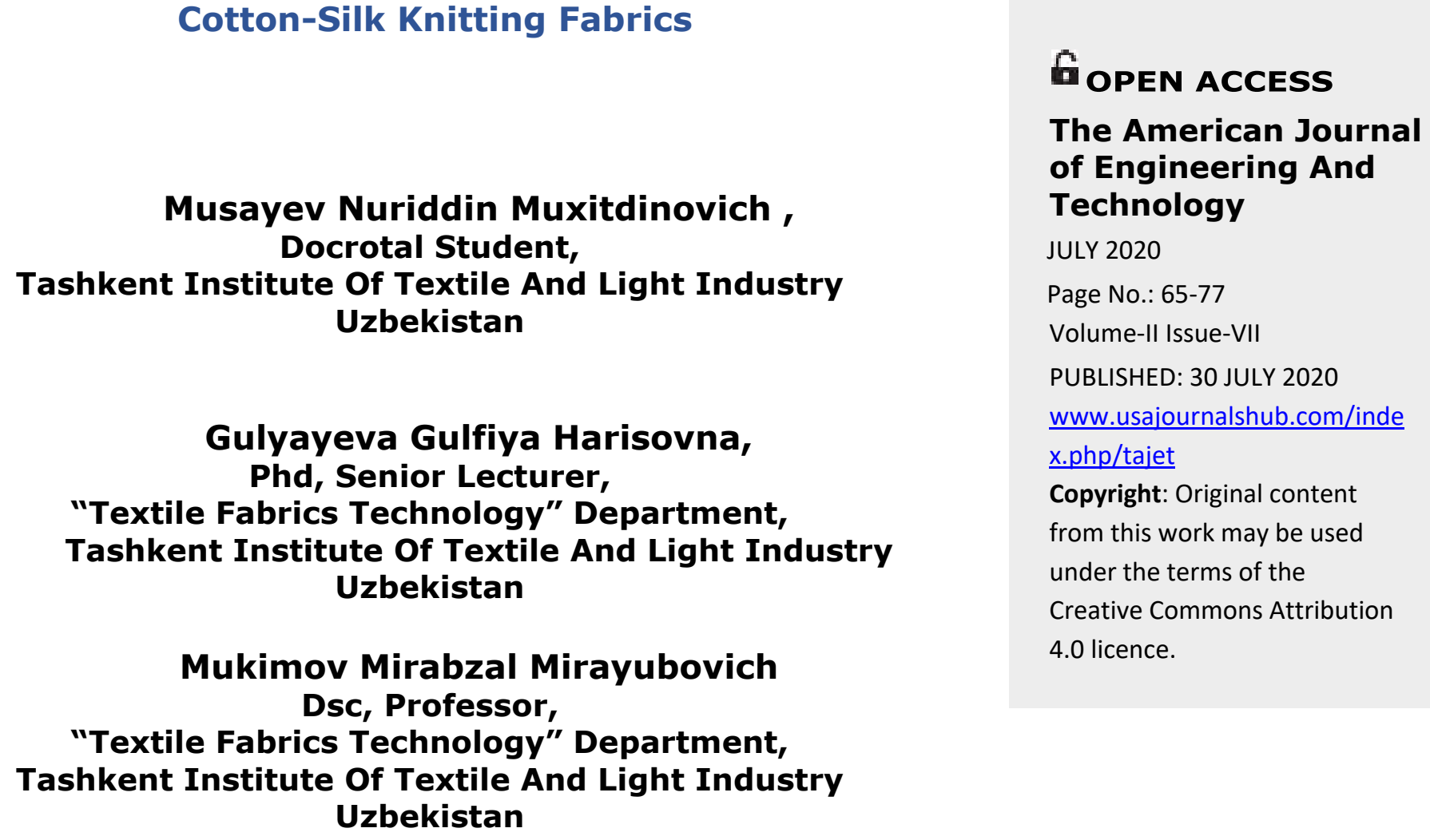

\title{
Abstract:
}

In recent years, the country has been actively working on the development of the textile, clothing and knitting industry, expanding the assortment and assortment of finished products, as well as supporting investment and export activities of the sector. In the article outlines the ways in which new knitted and knitted fabric can be used efficiently using local raw materials. Production of new types of knit fabrics using natural silk will not only expand the use of natural silk, but will also expand the range of knitted fabrics and improve their quality, consumption and especially hygienic properties. Manufactured cotton-silk knitted fabric was fabricated in a 18-gauage knitting machine made of Germany`s Mayer \& Cie OVJA 1.6 ET. In the article results of analyses of technological parameters patterned knitted fabrics, worked out with purpose effective using of locals raw materials and produced from 
ISSN (e): 2689-0984

DOI: https://doi.org/10.37547/tajet/Volume02Issue07-10

silk and cotton yarns is given. Implementation of the results will increase the competitiveness of manufactured products, increase the share of local raw materials processing and will allow to saturate the domestic market with high quality knitwear and to bring domestic products to the international market.

Keywords: pattern knitting, natural silk, spinning yarn, fabric, assortment, cotton, silk, technological parameters.

\section{Introduction}

One of the requirements for modern knitting fabrics in market conditions is competitiveness, which involves a set of consumer, functional and cost characteristics that determine the high demand for products on the market.

Among the knitted fabrics that have been successfully used in the manufacture of lightweight knitwear and underwear, webs of natural silk with improved hygienic properties are of particular interest.

Mainly in knitting fabrics, cotton and wool yarn are used, both in pure form and in a mixture with chemical, synthetic and artificial yarns.

Using the above types of raw materials, an assortment of knitted products with high consumer characteristics is obtained; durability, dimensional stability and beautiful appearance. Despite many positive qualities, these jerseys still have significant drawbacks, such as low hygroscopicity, poor air permeability and high thermal conductivity, which limit their use in regions with a hot climate.

For the Central Asian region, natural silk products are irreplaceable in their hygienic properties and will always be in great demand. Despite the fact that natural silk has a beautiful appearance, matte gloss, high strength and elasticity, good breathability and the ability to easily absorb moisture, its range is limited and is mainly used for the production of crepe and icat fabrics, although abroad it has a wider range of application.

The production of linen and lightweight knitwear made from cotton yarn in combination with natural fibers, namely natural silk, helps to improve consumer properties, 


\section{ISSN (e): 2689-0984}

DOI: https://doi.org/10.37547/tajet/Volume02Issue07-10

such as breathability, hygroscopicity, as well as hygienic properties, which allows their use in regions with a hot climate.

At present, the knitted equipment installed at the joint venture of Uzbekistan has wide technological capabilities, but unfortunately they have not yet been fully studied and disclosed, that is, the technological capabilities of these machines are not fully utilized. Studying and expanding the technological capabilities of modern knitting machines installed at enterprises in Uzbekistan, developing and developing new weave patterns from local raw materials on the above machines and subsequently expanding the range of knitted products with improved consumer properties are an urgent problem today.

To date, a number of research works have been carried out in the knitting industry by leading scientists in this field to develop new structures and methods for producing knitting fabrics. Of which: professors: A.S. Dalidovich, I.I. Shalov, L.A. Kudryavin, M.M. Mukimov; Associate professors: S.V. Kislyuk, L.M. Kukushkin and their students, in addition, scientists abroad: M. Savazaki, E. Harima, S. Yerisue and others.

And also studied the materials of the internet and literary sources for the production of knitwear using a natural type of raw material of our Republic, silk thread.

Recently, in this area a number of TITLI scientists are conducting research work. Of these, the works analyzed were Rakhimov A.Yu., Mirusmanov B.F., Abdurahimova F., Yunusov K.Z., Nabijanova N., performed under the guidance of professors Alimova H.A., Mukimov M.M. and relevant conclusions are drawn.

In [1], to carry out the necessary studies on the possibility of using cotton-silk yarn in knitting fabrics, samples were obtained from a circular knitting machine of a CT lined weave and a circular knitting machine of multiple elastic weaving. Moreover, on the "Multiripp" machine, in addition to cotton and silk yarn, polyester yarn was used.

To obtain knitwear, instead of cotton yarn, cotton-silk yarn with a linear density of 18,5 tex was used. In this case, cotton-silk yarn in one case was used as a lining thread, and in the other case, the main thread.

In work PhD. B.F. Mirusmanov developed a technology for producing cotton-silk linen knitting fabrics from natural silk threads and cotton yarn, combining high performance properties of cotton and silk $[2,3,4]$. 
The work has improved the technological process of preparing silk threads for processing on knit machines.

The regularities of the influence of the percentage of natural silk and cotton yarn in the weave variant on the technological parameters and the physico mechanical properties of the knitted fabric are established.

In work PhD. F. Abdurakhimova developed a technology for the production of hosiery from cotton-silk yarn $[5,6,7,8]$.

On the basis of a theoretical and experimental study of the analysis of the looping process using plated knitting, rational technological parameters for processing cotton-silk yarn on round-hobbing machines, such as the depth of cushioning, needle and buttonhole corners, the supply of soil, plated thread, the angle of culling and tension are recommended.

In work PhD. M. Umarova developed a technology for producing knitted fabrics with high heat-shielding properties, where silk yarn was used as a soil thread $[9,10,11,12]$.

The proposed options for plush, lined and plush-lined knitting fabrics were developed on round-loop machines of the LAMBDA type (Japan), circular knitting machines of the MONARCH type (USA), PILOTELLI (Italy).

In [13], the technology for producing knitted fabrics from cotton-silk yarn for linen and upper knitwear was improved.

A technology has been developed for the production of new assortments of linen and upper knitting fabric made of cotton-silk yarn, which allows expanding the technological capabilities of circular knitting machines and the scope of natural silk in knitting fabric.

As a result of experimental studies, it was found that from the point of view of technological reliability, the process of producing plated, combined and two-layer knitting fabrics from cotton-silk yarn proceeds more reliably than that of knitwear made from pure cotton yarn.

The work $[14,15,16]$ developed the technology and design of a new assortment of cotton-silk knitting fabrics.

The artistic and technological basis of a new assortment of cotton-silk knitting fabrics has been developed. Based on the study of the deformation properties of cotton and silk, the limit of the homogeneity coefficient of the raw material structure $(R c=0,4 \ldots 1,25)$ is 
established, which allows designing a bicomponent knitwear taking into account linear densities and the number of folds of the feedstock. DcS. K. Hholikov proposes to use silk yarn as a ground thread in the development of plated plush knitwear [17, 18, 19]. The proposed plush knitting fabric options were developed on a circular knitting machine of the ORIZIO type (Italy).

\section{Main Part}

In order to expand the range of knitted fabrics and to study the effect of the size of the pattern on the technological parameters and the physico-mechanical properties of the patterned cotton-silk knitting fabrics on the Mayer \& Cie OVJA 1.6 ET 18 gauage double jersey circular knitting machine, 5 variants of patterned cotton-silk knitting fabrics were developed, differing the size of the pattern on the surface of the canvas. The pattern on the surface of the canvas is formed by knitting an elastic series against the background of smooth weaving (Fig. 1).

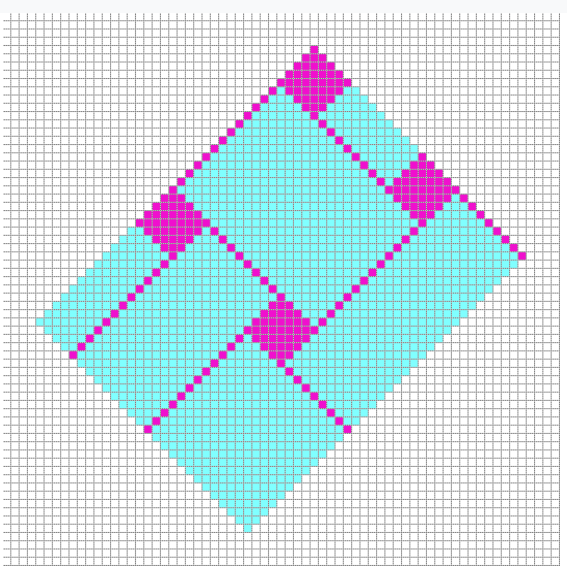

1-variant

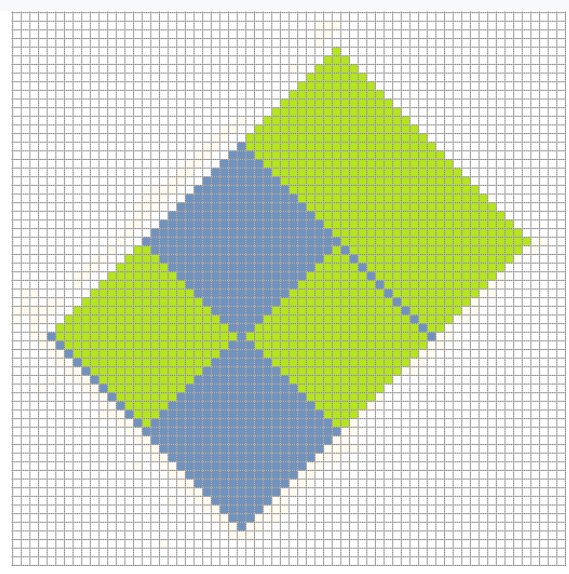

2-variant

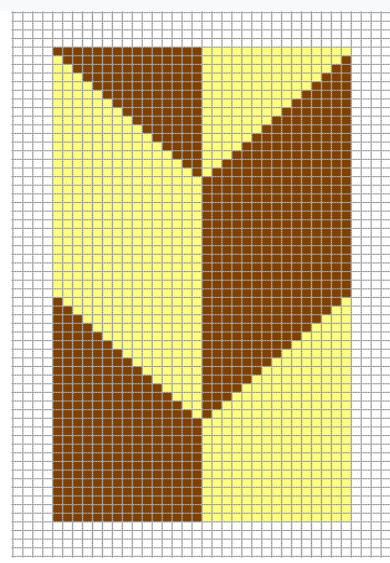

3-variant 


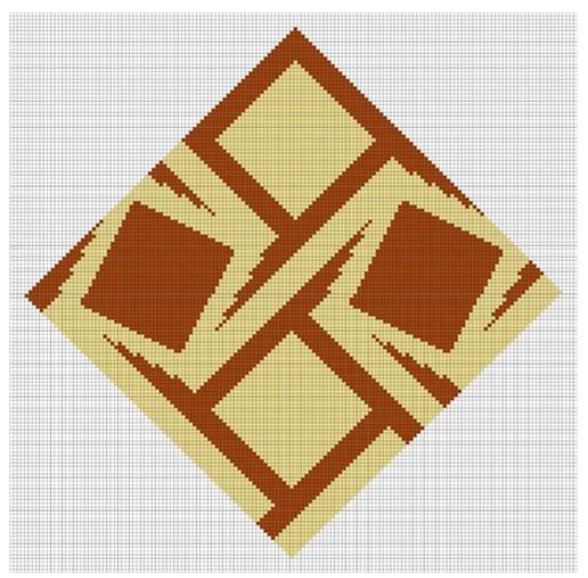

4-variant

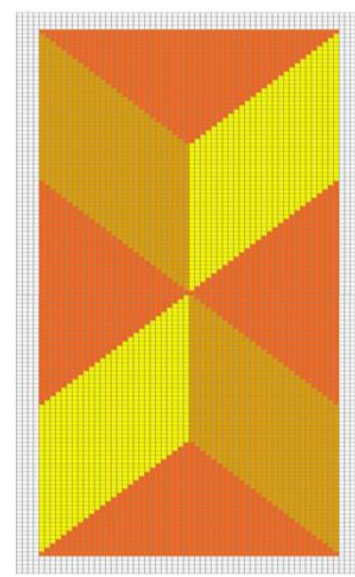

5-variant

Fig. 1. Structure patterned cotton silk knitting fabrics

Cotton yarn with a linear density of 25 tex and silk yarn with a linear density of 14,3 tex were used as raw materials.

For the basic version for comparing the parameters and properties of the new variants of the patterned cotton-silk knitting fabrics, the first variant of knitwear was adopted.

\section{Results And Discussions}

The technological parameters of the patterned cotton-silk were determined by the standard method in the "CentexUz" laboratory at TITLI, the results are shown in Table 1.

Based on the results of the analysis, technological parameters such as the loop step, the height of the loop row, the horizontal and vertical density, the length of the thread in the loop are determined.

Table 1

Technological parameters of cotton-silk knitted fabric samples

\begin{tabular}{|l|l|c|c|c|c|c|}
\hline \multicolumn{2}{|c|}{ Parametrs } & \multicolumn{5}{c|}{ Variants } \\
\cline { 3 - 7 } \multicolumn{2}{|c|}{} & I & II & III & IV & V \\
\hline \multirow{2}{*}{$\begin{array}{l}\text { Type and quantity of } \\
\text { yarn (thread) in sample }\end{array}$} & Cotton 25 tex & 54 & 58 & 56 & 60 & 42 \\
\cline { 2 - 7 } & Silk 14,3 tex & 46 & 42 & 44 & 40 & 1,0 \\
\hline \multirow{2}{*}{ Loop pitch A, mm } & Cotton & 0,88 & 1,0 & 0,96 & 1,0 & 1,04 \\
\cline { 2 - 7 } & Silk & 1,0 & 1,04 & 1,25 & 1,1 & 1,0 \\
\hline Hinge row height B, mm & Cotton & 1,1 & 1,0 & 0,9 & 1,1 & 1,0 \\
\hline
\end{tabular}




\begin{tabular}{|l|l|c|c|c|c|c|}
\hline \multirow{2}{*}{$\begin{array}{l}\text { The horizontal density } \\
\text { of the } \mathrm{R}_{\mathrm{G}} \text { loops }\end{array}$} & Silk & 0,91 & 1,0 & 0,9 & 0,91 & 50 \\
\cline { 2 - 6 } & Silk & 57 & 50 & 52 & 50 & 48 \\
\hline $\begin{array}{l}\text { The vertical density of } \\
\text { the } \mathrm{R}_{\mathrm{v}}, \text { loops }\end{array}$ & Cotton & 50 & 48 & 40 & 45 & 50 \\
\cline { 2 - 6 } & Silk & 55 & 50 & 55 & 55 & 3,8 \\
\hline \multirow{3}{*}{$\begin{array}{l}\text { Loop length I mm } \\
\text { From cotton yarn LG1, }\end{array}$} & 3,8 & 3,8 & 3,9 & 3,9 & 3,3 \\
\cline { 2 - 7 } & $\begin{array}{l}\text { From silk yarn LG2, } \\
\mathrm{mm}\end{array}$ & 3,2 & 3,3 & 3,3 & 3,4 & 3,4 \\
\cline { 2 - 7 } & From silk yarn LL3, mm & 3,5 & 3,4 & 3,5 & 3,5 & 118,8 \\
\hline Surface density Ms, gr/m ${ }^{2}$ & 122 & 118,8 & 139,1 & 110,2 & 118,5 \\
\hline Fabric thickness T, mm & 0,34 & 0,44 & 0,46 & 0,4 & 0,5 \\
\hline Volume density $\delta, \mathrm{mg} / \mathrm{sm}{ }^{3}$ & 358,8 & 270 & 302,4 & 275,5 & 237 \\
\hline Absolute volume density lightness $\Delta \delta, \mathrm{mg} / \mathrm{sm}^{3}$ & - & 88,8 & 56,4 & 83,3 & 121,8 \\
\hline Related volume density lightness $\theta, \%$ & - & 25 & 16 & 23 & 34 \\
\hline
\end{tabular}

Note: $L_{G 1}$ - the length of the thread in the loop of the surface of cotton yarn; $L_{G 2}$ the length of the thread in the loop of the surface of silk yarn; $L_{L 3}$ - the length of the thread in the loop of an eraser made of silk yarn.

An analysis of the results of studies conducted by many scientists showed that a decrease in the surface density of knitting fabric wear is the least dangerous for its strength properties, since the absolute value of the strength of knitting fabric is high, during operation, the products are subjected to loads not exceeding $20 \%$ of breaking [20].

The decrease in surface density causes damage to the hygienic and heatshielding properties of the canvas.

Therefore, it seems rational to introduce an indicator that would simultaneously characterize both the material consumption of the canvas and its qualitative indicators.

Such an indicator is an indicator of the lightness of the structure of knitting fabrics, in which, along with the surface density, its thickness is also taken into account. An indicator of the lightness of the structure of knitwear can use volume density: 


$$
\delta=\frac{M}{T} ; m g / s m^{3}
$$

where, $\delta$ - is the volume density of the knitting fabrics, $\mathrm{mg} / \mathrm{sm}^{3}$;

$\mathrm{M}_{\mathrm{S}}$ - surface density of knitting fabrics, $\mathrm{g} / \mathrm{m}^{2}$;

$\mathrm{T}$ - is the thickness of the knitting fabrics, $\mathrm{mm}$.

Since knitwear is a three-dimensional structure characterized by length, width and thickness, the lightness of this structure should be determined not by a two-dimensional criterion (surface density), but by three-dimensional (volume density).

The "volume density" indicator reflects the tenacity of knitting fabric in space. The volume density of knitting fabrics shows the content of textile yarns per unit volume. When using volume density as a criterion for the lightness of the structure of knitting fabrics, the concept of "lightness" expands. At the same time, canvases with a loose structure, having a significant thickness, are included in the discharge of paintings with reduced material consumption, compared with the base ones. Hence, canvases with reduced material consumption are called canvases whose volume density is lower than that of the base, associated with the optimal module of the loop of identical yarn.

The surface density of the proposed options for cotton-silk patterned knitting fabric varies from 110,2 to $139,1 \mathrm{~g} / \mathrm{m}^{2}$, the lowest surface density in the IV option of knitting fabric is $110,2 \mathrm{~g} / \mathrm{m}^{2}$ (Table 1 , Fig. 2).

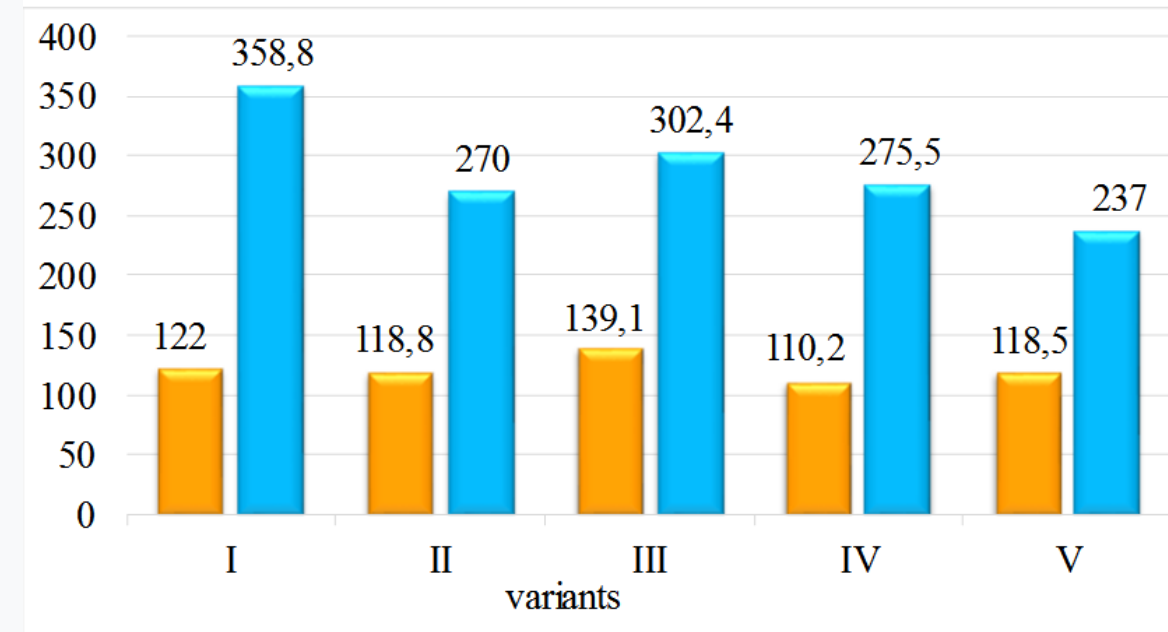

$\square$ Surface density Ms, gr $/ \mathrm{m}^{2} \quad \square$ Volume density $\delta, \mathrm{mg} / \mathrm{sm}^{3}$ 
Fig. 2. Histogram of changes in surface and volume density of cotton-silk patterned knitting fabrics

The volume density of the patterned cotton-silk knitting fabric options from 237 to $358,8 \mathrm{mg} / \mathrm{sm}^{3}$, the lowest volume density for the $\mathrm{V}$ option of knitting fabrics is $237 \mathrm{mg} / \mathrm{sm}^{3}$. The results of the study showed that the volume density of the developed fabrics of cottonsilk patterned knitting fabric is less compared to the basic weave (option- I), (table 1, figure 2).

If the surface density of the base knitting sample is $M s=122 \mathrm{~g} / \mathrm{m}^{2}$ and the thickness $\mathrm{T}=0,34 \mathrm{~mm}$, its volume density is $\delta=358,8 \mathrm{mg} / \mathrm{sm}^{3}$.

In this case, the absolute volumetric relief indicators of the canvases compared to the base weave will be as follows (Table 1, Fig. 3):

$$
\begin{array}{rlr}
\Delta \delta & =\delta_{\sigma}-\delta=358,8-270=88,8 \mathrm{mg} / \mathrm{sm}^{3} & \text { (II opt.) } \\
\Delta \delta & =\delta_{\sigma}-\delta=358,8-302,4=56,4 \mathrm{mg} / \mathrm{sm}^{3} & \text { (III opt.) } \\
\Delta \delta & =\delta_{\sigma}-\delta=358,8-275,5=83,3 \mathrm{mg} / \mathrm{sm}^{3} & \text { (IV opt.) } \\
\Delta \delta & =\delta_{\sigma}-\delta=358,8-237=121,8 \mathrm{mg} / \mathrm{sm}^{3} & \text { (V opt.) }
\end{array}
$$

Here: $\Delta \delta$ - absolute volumetric relief, $\mathrm{mg} / \mathrm{sm}^{3}$;

$\delta_{\delta}$ - is the volume density of the base knit sample, $\mathrm{mg} / \mathrm{sm}^{3}$;

$\delta$ - is the volume density of the test web, $\mathrm{mg} / \mathrm{sm}^{3}$;

The relative relief of the developed patterns of cotton-silk patterned knitting fabrics is as follows:

$$
\begin{aligned}
& \left.\theta=\left(1-\frac{\delta}{\delta_{\sigma}}\right) \cdot 100 \%=\left(1-\frac{270}{358,8}\right) \cdot 100 \%=25 \% \quad \text { (II opt. }\right) \\
& \left.\theta=\left(1-\frac{\delta}{\delta_{\sigma}}\right) \cdot 100 \%=\left(1-\frac{302,4}{358,8}\right) \cdot 100 \%=16 \% \quad \text { (III opt. }\right) \\
& \left.\theta=\left(1-\frac{\delta}{\delta_{\sigma}}\right) \cdot 100 \%=\left(1-\frac{275,5}{358,8}\right) \cdot 100 \%=23 \% \quad \text { (IV opt. }\right)
\end{aligned}
$$




$$
\theta=\left(1-\frac{\delta}{\delta_{\sigma}}\right) \cdot 100 \%=\left(1-\frac{237}{358,8}\right) \cdot 100 \%=34 \% \quad(\mathrm{~V} \text { opt. })
$$

As can be seen from Fig. 2.3, the smallest consumption of raw materials in the development of cotton-silk patterned knitting fabrics is required for the $\mathrm{V}$ option of knitting fabric, i.e. the volume density of this knitting fabric is the smallest compared to other options.

Reducing the consumption of raw materials in the development of the II, III, IV, V variants of cotton-silk patterned knitting fabrics is achieved by reducing the number of elastic knitting loops, since the rapport of cotton-silk patterned knitting fabrics consists of knitting and ironing loops.
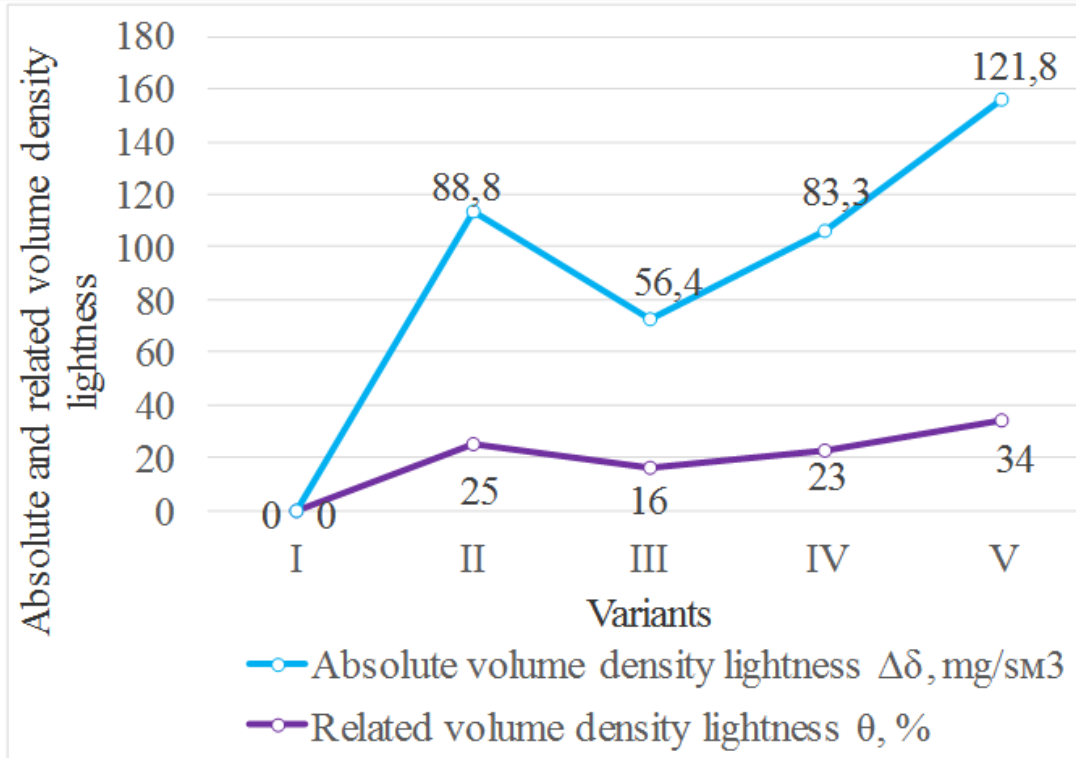

Fig. 3. Histogram changes absolute volumetric relief and relative lightness of cottonsilk patterned knitting fabrics.

\section{Conclusion}

In conclusion, it can be noted that by changing the size of the pattern on the surface of the cotton-silk patterned knitting fabrics, it is possible to obtain knitwear with desired properties and reduced material consumption.

The developed fabrics of pattern cotton-silk knitting fabrics can be successfully used in the manufacture of lightweight upper products and children's assortment. 


\section{References}

1. A.Yu. Rakhimov Basics of processing technology in spinning cotton wool from industrial cocoons. Dis. Cand. tech. sciences. Tashkent. TITLP. 1994 year.

2. H.A. Alimova, M.M Mukimov, B.F. Mirusmanov. Features of the production of formstable knitting fabrics using cotton yarn and natural silk. // Actual problems of food, light industry and service sector. Azerbaijan Institute of Technology: Abstracts. report int. scientific and technical conf. -Ganja. 1999. 56 p.

3. M.M Mukimov, B.F. Mirusmanov. Cotton-silk knitting fabric. MSTU: Abstracts. report on the all-Russian scientific tech. conf. Moscow State Textile University. A.N. Kosygin. Moscow. 2003. 52 p.

4. R.S. Karimzhanova, B.F. Mirusmanov, T.M. Movlonov. Investigation of the deformation properties of cotton-silk knitting fabrics based on the theory of viscoelasticity. // J. Problems of textiles. 2004. №. 2. 37-39 pp.

5. F.A. Abdurakhimova, H.A. Alimova, Sh.R. Ikramov. Features of the production of hosiery from cotton-silk yarn of various options. // J. Problems of textiles. №. 4. 2002 46$48 \mathrm{p}$.

6. Sh.R. Ikromov, F.A. Abdurakhimova, N.B. Esonova, B.S. Mazlov. The main indicators of the physical and mechanical properties of silk and cotton yarn. // J. Problems of textiles. № 1. 2003 39-41 p.

7. F.A. Abdurakhimova, Sh.R. Ikromov. Investigation of the physical and mechanical properties of hosiery from cotton-silk yarn. // J. Problems of textiles.

№ 1.2005 54$57 \mathrm{p}$.

8. F.A. Abduraximova, X.A. Alimova, Sh.R. Ikramov. Expansion of assortment of hosieries from cotton-silk yarn. // Proceeding of the scientific conference of the participants of training course in Shanghai university in the field of engineering: Scientific report of Shanghai university. 2006 y. 60-62 pp.

9. M.N. Umarova, G.T. Khudaynazarova, F.M. Yusupova, M.M. Mukimov Effective using of locals raw materials cotton and silk plush jersey // J. Problems of textiles. - T., 2004. №. 2. 17-19 pp.

10. M.N. Umarova, G.T. Khudaynazarova, M.M. Mukimov. Cotton and silk plush jersey 
// J. Problems of textiles. - T., 2004. - №. 4. 21-24 pp.

11. M.N. Umarova, B.F. Mirusmanov, A.E. Isabaev, M.M. Mukimov. Cotton and silk fleecy jersey // J. Problems of textiles. - T., 2005. - №. 4.28-30 pp.

12. M.N. Umarova, A.E. Isabaev, B.F. Mirusmanov, M.M. Mukimov. Comprehensive assessment of the quality of cotton and silk plush jersey. // Materials int. scientific-practical conf. "Infotextile-2005". Implementation of information and communication technologies in the textile and light industry. - Tashkent, 2005. - 318-320 pp.

13. K.Z. Yunusov, R.S. Karimjonova, B.F. Mirusmanov, M.M. Mukimov Cotton - silk knitting fabrics // J. Problems of textiles. - T., 2004. - №. 4. 44-48 pp.

14. N.N. Nabidjanova, K.Z. Yunusov, F.Kh. Rakhimov, M.M. Mukimov Development of new structures of cotton-silk knitwear // J. Prob. textiles. - T., 2006. -№1. 65-68 pp.

15. N.N. Nabidjanova, F.Dj. Abdulina, F.U. Nigmatova, I.G. Shin. Substantiation of the parameters of the structure of the upper cotton-silk knitted fabric. // J. Prob. tex. - T., 2007. - №.2, 28-30 pp.

16. N.N. Nabidjanova, H.A. Alimova, I.G. Shin, F.U. Nigmatova. Designing cotton-silk knitwear based on the momentless shell theory. // J. Problems of textiles. - T., 2007. - №. 3, 52-55 pp.

17. K. Holikov, M. Mukimov. Investigation of the properties of cotton-silk plush jersey. // Collection of scientific papers of the 2 nd international scientific and technological complex "Quality in production and socio-economic systems". -c. Kursk, 2014 2-volume. 186-188 pp.

18. M.M. Mukimov, K. Holikov, H. Hazratkulov, Sh. Usmonkulov. Study of the influence of the

type of raw materials on the quality indicators of plush knitwear. // Materials of the international scientific and industrial complex "Education and science in the conditions of social modernization of Kazakhstan society." Taraz, TIGU, 2013 2-volume, 29-31 p.

19. M.M. Mukimov, K. Holikov, H. Hazratkulov, M. Musaeva. Cotton-silk plush jersey. // Materials of the international scientific forum "PROGRESS-2013". Ivanovo, 2013, 204$207 \mathrm{pp}$. 


\section{THE AMERICAN JOURNAL OF ENGINEERING AND TECHNOLOGY}

ISSN (e): 2689-0984

DOI: https://doi.org/10.37547/tajet/Volume02Issue07-10

20. Yu.S. Shustov Fundamentals of Textile Materials Science. -M.: OOO "Sovyaj Bevo" 2007, 307 p. 